\title{
PISTIS SOPHIA
}

Ein gnostisches Originalwerk des dritten Jahrhunderts aus dem Koptischen übersetzt

In neuer Bearbeitung. mit einleitenden Untersuchungen und Indices

herausgegeben

von

D. Dr. CARL SCHMIDT

Professor der Theologie an der Universität Berlin

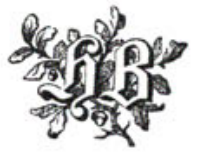

Leipzig

J. C. Hinrichs'sche Buchhandlung

1925 
Copyright 1925

by J. C. Hinrichs'sche Buchhandlung, Leipzig

Printed in Germany 


\section{Herrn Hofrat Röhrer-münchen}

dem wirksamen Förderer und treuen Begleiter auf der Sinai-Expedition

um deren reiche Früchte der Weltkrieg die Wissenschaft und das Vaterland

gebracht hat 
